\title{
CT SCAN BASED EVALUATION OF SPLENIC INDEX IN PATIENTS FROM LUCKNOW AND ADJOINING AREAS
}

\author{
Prince Kapoor, Vineeta Tewari, PK Sharma, Mumal Nagwani, Tahsin Munsif, \\ Geetanjali Srivastava, Sonia Jaiswal, Archana Srivastava \\ Department of Anatomy, Era's Lucknow Medical College and Hospital, Lucknow, UP, India
}

\begin{abstract}
Introduction: The Indian subcontinent is an endemic zone for diseases like malaria and filaria which alter the size of spleen to a variable extent. In order to identify and examine the spleen accurately, the modes of investigation that are at our disposal are Ultrasonography, Computerised Tomography, Magnetic Resonance Imaging and Radionuclide Scan. Linear dimensions are of limited use as a guide to normal splenic size on CT because the spleen is irregular in shape and is obliquely oriented within the left upper quadrant. A more accurate approach to the assessment of splenic size is the splenic index. Sufficient and reliable data for its normal values are lacking. The objective of the present study was to generate normative data of splenic index which could be used as a research and clinical tool.

Material \& Methods: It was an open randomized study carried out on 80 adults between 20 to 70 years of age. Spleen was identified in each transverse, coronal and sagittal section image of helical CT scan.

Results: The average splenic index, calculated as a product of the three measured linear dimensions of spleen i.e. length, breadth and thickness, in males was $369.89 \mathrm{~cm}^{3}$ and in females $298.61 \mathrm{~cm}^{3}$. The mean splenic index was calculated as $342.62 \mathrm{~cm}^{3}$.

Conclusion: The results can be used for evaluating patients with suspected splenomegaly, in certain clinical situations where objective measurement of splenic dimensions and comparison with normal values is required, and in drafting of government policies and programs related to malaria and filaria control where these normal values of splenic index help by identifying populations more susceptible to such infections.
\end{abstract}

Keywords: Spleen, splenomegaly, splenic index, computerised tomography.

\section{INTRODUCTION}

Spleen is an ovoid, purplish organ, about the size and shape of one's fist, located in the superolateral part of the left hypochondrium of the abdomen [1]. The size and weight of spleen vary with age and sex. It can also vary slightly in the same individual under different conditions [2]. Usually, the spleen is not palpable in adults [3]. In majority of cases, if its lower edge can be palpated, it is enlarged about three times its normal size [1]. So, palpation is not a reliable method for determination of spleen size [4]. Normally crescentic spleen appearing somewhat spherical and its extension anterior to the aorta or below the right hepatic lobe or rib cage are further clues to splenomegaly.

In order to identify and examine the spleen accurately, we usually have to rely on certain investigations. The modes of investigation generally used are Ultrasonography, Computerised Tomography, Magnetic Resonance Imaging and Radionuclide Scan [5].

Ultrasonography is most commonly used in routine practice for examining spleen but this method can be inaccurate since the contour of spleen is variable. It is difficult to scan the entire spleen completely in one 
sitting due to bone, bowel gas or left kidney intervening between the ultrasound probe and spleen. Therefore, Computerised Tomography is considered to be more reliable than Ultrasonography as far as examination of spleen is considered [5].

Diagnosing a large number of diseases incorporates the assessment of splenic size as this organ gets enlarged to a variable extent in a variety of disorders [6]. Many observers while studying spleen generally rely on their personal experience in order to judge the splenic volume.

The spleen measures 12 to $15 \mathrm{~cm}$ in length, 4 to 8 $\mathrm{cm}$ in width, and 3 to $4 \mathrm{~cm}$ in thickness [7]. These measurements are of limited use as a guide to normal splenic size on CT due to the spleen's irregular shape and oblique orientation within the left upper quadrant,

A more accurate approach to the assessment of splenic volume is the splenic index. Splenic Index [SI] is a research tool. It is a volumetric index and is used as an indicator in surveillance of malaria.

A high splenic index is generally of no concern. A low splenic index indicates a compromised immune system. This is usually an indication that the spleen is not producing an adequate amount of lymphocytes leading to a weakened immune system. Consequently, susceptibility to infections like malaria and filaria is increased. Thus, the $\mathrm{SI}$ is used as an indicator for immunity against malaria and filarial infection. Population having high $\mathrm{SI}$ is considered less susceptible or immune to such kind of parasitic infections [8].

In the Indian population, calculation of the normal splenic index becomes difficult since in endemic diseases like malaria and filaria, a variable change in the size of spleen is seen.

\section{MATERIALS AND METHODS}

The present study was conducted in the Department of Anatomy in collaboration with the Department of Radiodiagnosis at Era's Lucknow Medical College and Hospital, Lucknow, Uttar Pradesh, India. Patients were recruited from the Radiodiagnosis department. Inclusion criteria was adults between 20 to 70 years of age [9]. Exclusion criteria were abnormal appearance of spleen on CT scan, diagnosed cases of pathologies involving the spleen, where the entire length of the spleen could not be properly documented, fever at least four weeks prior to the scan and pregnancy.
Informed consent was taken. Medical history of all subjects was reviewed. Spleen was identified in each transverse, coronal and sagittal section image of helical CT scan. CT was performed on SIEMENS SOMATOM FORCE, 384 slice machine, by a single observer.

For maximum length of spleen, craniocaudal length was measured from the most superior margin to the most inferior margin of the spleen in coronal section image [10]. Maximum width and thickness were measured on the transverse section images. Width was measured as the greatest overall dimension. Thickness was measured as the perpendicular distance between the hilum and the outer convex surface of the spleen (Fig. 1) [10].

The Splenic Index (SI) was calculated as: $\mathbf{S I}=$ length $x$ width $x$ thickness $(\mathrm{cm})$

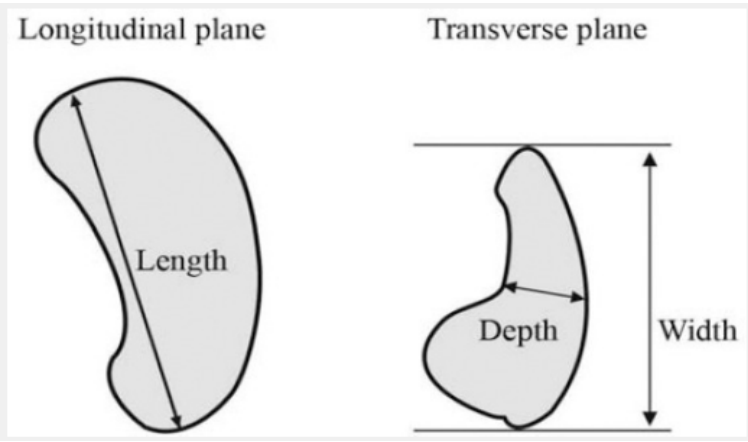

Fig. 1: Method of measuring the linear dimensions of spleen

\section{OBSERVATIONS}

In the present study, a total of 80 participants were recruited aged between 20 to 70 years and was divided into five groups (Table 1). Out of these, 54 were males (67.5\%) and 26 females (32.5\%).

Table 1: Age-wise demographic profile of the study population

\begin{tabular}{|l|c|c|}
\hline Age (years) & No. & $\%$ \\
\hline $20-30$ & 15 & 18.8 \\
\hline $31-40$ & 14 & 17.5 \\
\hline $41-50$ & 27 & 33.8 \\
\hline $51-60$ & 13 & 16.3 \\
\hline$>60$ & 11 & 13.8 \\
\hline Mean Age $\pm S D$ & $45.11 \pm 14.12(20-75)$ \\
\hline
\end{tabular}


A significant association was found between age and splenic parameters. There was a steady increase in the splenic index till the beginning of $4^{\text {th }}$ decade of life. Thereafter, with advancing age, there was a significant reduction in the mean value of splenic index (Fig. 2).

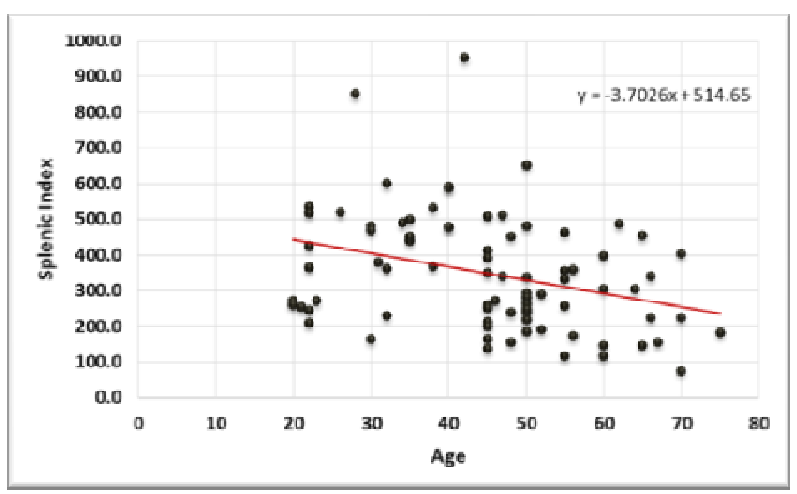

Fig. 2: Graph showing correlation of age with splenic index

The average length of spleen in males, measured craniocaudally, was $9.69 \mathrm{~cm}$ and in females, it was $9.29 \mathrm{~cm}$, average of the two being $9.57 \mathrm{~cm}$. The average width was measured as $8.85 \mathrm{~cm}$ in males and $8.22 \mathrm{~cm}$ in females, average of the two being $8.65 \mathrm{~cm}$. The average thickness of spleen in both males and females was $4.06 \mathrm{~cm}$.

The average splenic index was calculated as a product of the three measured linear dimensions of spleen i.e., length, width and thickness. In males, it came out to be $369.89 \mathrm{~cm}^{3}$ while in females, it was $298.61 \mathrm{~cm}^{3}$. The mean splenic index was calculated as $342.62 \mathrm{~cm}^{3}$ (Fig. 3).

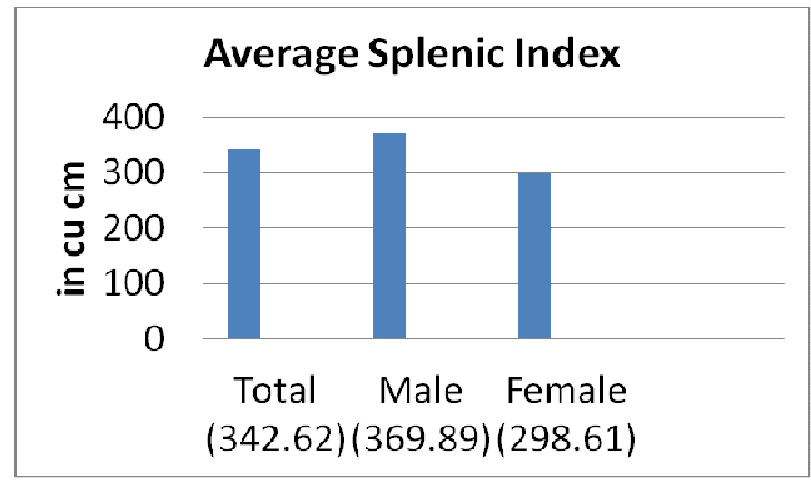

Fig. 3: Bar diagram showing average splenic index of the study population

\section{DISCUSSION}

We found that gender did not affect the splenic index, however a significant association was found between age and splenic parameters. There was a steady increase in the splenic index till the beginning of $4^{\text {th }}$ decade of life. Thereafter, with advancing age, there was a significant reduction in the mean value of splenic index.

The splenic index did not show significant sexual difference though female had a lesser value (male $369.89 \mathrm{cu} \mathrm{cm}$ and female $298.61 \mathrm{cu} \mathrm{cm}, \mathrm{p}<0.160$ ).

Strijk et al. (1987) had measured the splenic index and gave a mean value of 449 on European population [11] which is considerably higher than the value we got in our study i.e. $342.62 \mathrm{~cm}^{3}$.

Grissom and Shintr (1998) calculated his upper normal value as $425-450 \mathrm{~cm}^{3}(20)$ which again is more than what we have found. They calculated the splenic index by multiplying the greatest anteroposterior, transverse and length of the spleen. This is usually by CT measurements although MRI or USG could also be used [12].

Jong et al. (2009) defined the upper limit of normal for splenic index as $725 \mathrm{~cm}^{3}$. They found a mean value of $395 \pm 163 \mathrm{~cm}^{3}$ for splenic index in their study on 111 subjects [13]. This again was more than our finding. The normal value of splenic index is around $480 \mathrm{~cm}^{3}$ [13].

So, we found that the splenic index of Indian adult population residing in the area of our study lies below the range given for European and American population and it is much less than the normal value of splenic index which is 480 . This makes them much more susceptible to infections like malaria and filaria.

We also found that splenic index, when calculated as the product of splenic length, width and thickness, is a simple and rapid procedure. This is especially helpful when we are defining splenic size in vivo. The splenic index is also a needful tool to assess splenomegaly.

Before diagnosing splenomegaly, it is necessary to know the normal value of splenic index. This value becomes even more important in context of the Indian subcontinent because this region is an endemic zone of infections like malaria and filaria. 


\section{CONCLUSION}

The aim of this work was to determine the normal splenic index in North Indian adult population and compare it with the published data.

The results provide a normal value of splenic index for a part of the population and hence suggest that a lower cut off value is needed for making a diagnosis of splenomegaly. Splenic index can be used for evaluating patients with suspected enlargement of spleen. The findings can also be helpful in certain clinical situations where splenic dimensions and comparison with normal values is required. The Splenic index can also be used in drafting of government policies and programs related to malaria and filaria control where normal values of splenic index may help in identifying populations susceptible to infections.

\section{REFERENCES}

1. Moore KL, Dalley AF, Agur AMR. Clinically Oriented Anatomy, $6^{\text {th }}$ ed., Lippincott Williams \& Wilkins, Philadelphia. 2010, pp. 263-281.

2. Standring S. Gray's Anatomy International Edition: The Anatomical Basis of Clinical Practice, $40^{\text {th }}$ ed., Churchill Livingstone, 2008, pp.1191-5.

3. Darwish H Badran, Heba M Kalbouneh, Maher T Al-Hadidi, Amjad T Shatarat, Emad S Tarawneh, Azmy M Hadidy, Waleed $S$ Mahafza. Ultrasonographic assessment of splenic volume and its correlation with body parameters in a Jordanian population. Saudi Med J. 2015; 36(8): 967-972.

4. Singh A, Das JK, Chandra N, Ansari H. Ultrasonographic measurement of splenic length in relation with body surface area in adults of Bihar J Anat Sciences. 2015; 23(1): 5-9.
5. Asghar A, Naaz S, Agarwal D. Morphometric study of spleen in North Indian adult population: Ct scan image based study. JCDR. 2011; 5 (5): 974-977.

6. Arora N, Sharma PK, Sahai A, Singh R. Ultrasonographic measurement of the spleen: splenic length in adults and its correlation with different parameters. J Anat Soc India. 2013; 62 (2): 57-61.

7. Joseph KT Lee, Stuart S Sagel, Robert J Stanley, Jay $P$ Heiken. Computed body tomography with MRI correlation. $4^{\text {th }}$ ed. Vol. 2, Lippincott Williams \& Wilkins; 2005, Vol.2.

8. Asghar A, Naaz S, Agarwal D. Estimation of standard splenic index (SI) in Indian population: A CT scan based study. Indian J Basic and Applied Medical Research. 2014; 3 (2): 332-337.

9. Siddiqui MA, Ali AHA, Bedewi MA, Serhan OO. Estimation of standard splenic volume in Saudi Arabian adult population: Using 3D reconstruction of abdominal CT scan images. Open Journal of Internal Medicine. 2014; 4: 7-12.

10. Yetter EM, Acosta KB, Olson MC, Blundell K. Estimating splenic volume: sonographic measurements correlated with helical CT determination. AJR Am J Roentgenol. 2003; 181 (6):1615-20.

11. Strijk SP, Boetes C, Bogman MJJT, De Pauw BE, Wobbes Th The Spleen in Non-Hodgkin Lymphoma: Diagnostic value of computed tomography. Acta Radiologica 1987; 28(2): 139-144.

12. Grissom $\mathrm{L}$ and Shintr. Splenic index.Message-ID: <3668BF1C.34C351F9@earthlink.net> and message ID: <19981201162157.26188.00000693@ng137.aol.com> sci.d.radiology 1998 [cited on 2011 July 17].

13. Pim A. de Jong, Henriette M. Quarles van Ufford, Henk-Jan Baarslag, Marie J. de Haas, Shulamiet H. Wittebol, Lorentz G. Quekel and John M. de Klerk. CT and 18F-FDG PET for noninvasive detection of splenic involvement in patients with malignant lymphoma. American Journal of Roentgenology. 2009; 192 (3): 745-753 